\title{
The Structure of Gold Alloys in the Liquid State
}

\section{NOVEL QUENCH PRODUCTS FROM SOME EUTECTIC SYSTEMS}

\author{
V. G. Rivlin, R. M. Waghorne and G. I. Williams \\ Fulmer Research Institute, Stoke Poges, Buckinghamshire, England
}

The structure of molten gold and its alloys is discussed with reference to the packing of atoms in the liquid phase. When the packing is compared with that of the underlying equilibrium solids there is shown to be a pronounced disparity which can account for expansion effects on solidification and for many unusual metastable phases obtained by high-speed quenching from the liquid phase, some of which may well have industrial applications.

The role of liquid structures during solidification of metals and alloys has seldom received much attention. Certainly the foundry metallurgist views the growth of crystalline nuclei as being developed by abstracting atoms from a random pool of the components in the liquid phase. The actual crystal symmetry and the microscopical morphology of the products of solidification are, in general, discussed without more than cursory reference to the packing of atoms in the liquid. We propose to discuss the liquid structures of gold and gold-based alloys and to show two ways in which these liquid structures may have a bearing on the solidified materials.

\section{Liquid Metal Structures}

Until quite recently many investigators have preferred random models for the packing of atoms in the liquid phase of any metals or alloys $(1,2)$. The issue can still be controversial. However, it is now apparent from diffraction studies that not all metallic liquids can be allotted the same structure. For some binary alloy systems it has even been proved that atomic packing varies with composition $(3,4,5)$.

The structure of liquid gold is now well-established. $\mathrm{X}$-ray studies of the liquid phase show that gold may be classified with other typical metals as having a structure best described in terms of random closepacked assemblies of spherical atoms (the hard-sphere model). According to this model the liquid is essentially a disordered version of the crystal structure in the metallic solid, which is also close-packed. This disordering, or absence of long-range order, in the liquid gives rise to a change in density. When the densities of liquid and solid gold are compared at the freezing point, $1064^{\circ} \mathrm{C}$, the greater density of the solid, $18.2 \mathrm{~g} \mathrm{~cm}^{-3}$ compared with 17.3 for liquid gold (6), shows that gold, like any typical metal, must shrink on freezing. For gold the percentage volume change on solidification is 5.1 per cent.

Examination of elements which are not wholly metallic, i.e., the semi-metals silicon, germanium, antimony, indium, gallium, etc., reveals quite a different situation. All such elements expand on solidification by amounts varying between 3 and 10 per cent $(7,8)$. Silicon and germanium both have a crystalline structure which is the antithesis of metallic, the covalently bonded A-4 structure (diamond cubic), with open-packed tetrahedral symmetry and a correspondingly low density. The liquid, however, is more metallic as evidenced not only by an increased electrical conductivity but also by an increased density $(7,8)$. Thus, on melting silicon or germanium a radical atomic rearrangement takes place to give a structure more close-packed than the tetrahedrally coordinated solids, but not sufficiently close a packing to be directly interpreted in terms of the hard-sphere model. X-ray investigations provide evidence in support of this deduction $(9,10)$.

\section{Structures of Liquid Gold Alloys}

The situation becomes more complex when gold is alloyed with such a semi-metal. The systems goldsilicon and gold-germanium are typical examples. Both have simple eutectic equilibrium diagrams with no intermediate phases. There is only a little, mutual solid solubility between the components, due to the large atomic size factors. In the liquid phase, however, gold is miscible with silicon or germanium. $\mathrm{X}$-ray spectra of these alloys show that up to 25 to 


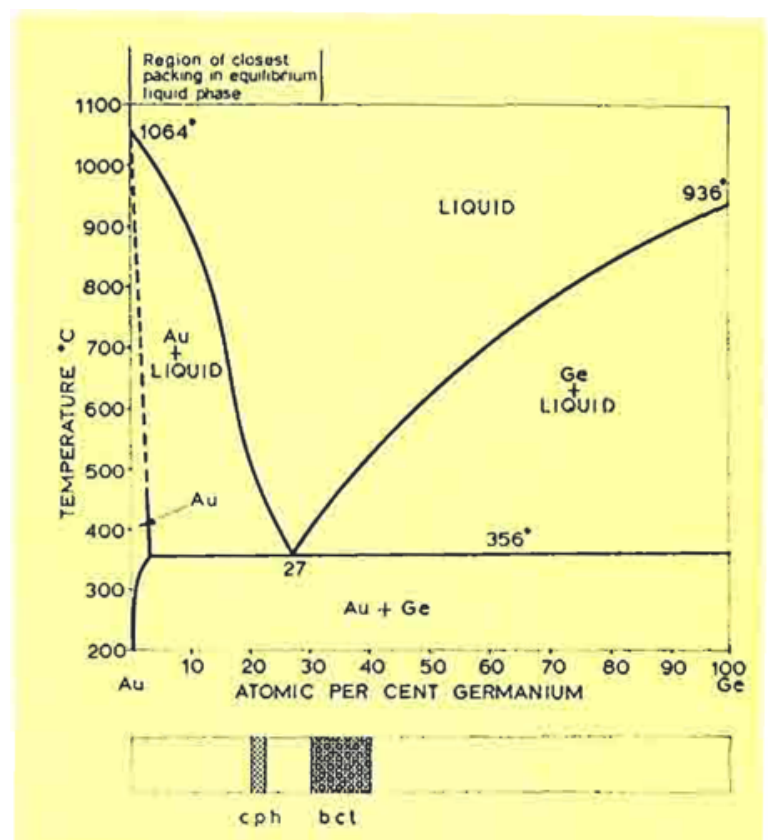

Fig. 1 The homogeneity range of two metastable gold-germanium phases obtained by splat-cooling (ref. 21) in relation to the gold-germanium equilibrium diagram (From Hansen and Anderko, Constitution of Binary Alloys, Wiley, New York, 1958) Metastable crystal structures: c.p.h. close-packed hexagonal ( $\zeta$-phase) b.c.t. body-centred tetragonal

30 atomic per cent silicon or germanium the liquids are close-packed like pure gold, and the structure is amenable to interpretation in terms of the hard-sphere model. In other words, the silicon or germanium is simply incorporated into the structure of liquid gold itself, to form a "solution", the liquid counterpart of a solid solution. Just as in the case of solid phases, a maximum solubility seems to exist. Gold alloys with more than 25 to 30 atomic per cent of the IV B element have complex X-ray spectra best interpreted in terms of the gradual introduction of the relatively more open packing characteristic of the liquid semimetals (5). It is a general rule for gold alloys that the region of closest packing in the liquid phase is to be found in the gold-rich region as indicated in Figure 1.

Various authors have speculated that optimum compositions for liquid packing occur at the eutectic compositions (see, e.g., ref. 11). Chen and Turnbull $(12,13)$ go further and claim on thermodynamic grounds, that the eutectic composition in gold-silicon (18.6 atomic per cent silicon) is associated with an ideal ratio of gold and silicon atoms favouring strong gold-silicon attractive bonding which stabilises the liquid at the expense of the solid. This interpretation would account for the abnormally low eutectic melting temperature, about $363^{\circ} \mathrm{C}$ according to the latest data (14), compared with $1420^{\circ} \mathrm{C}$ and $1064^{\circ} \mathrm{C}$ for silicon and gold respectively. An analogous interpretation may be applied to gold alloys with germanium (5).

\section{Expansion on Solidification}

The structural disparity between the liquid and solid phases of gold alloys in these simple eutectic systems is confirmed by unusual expansion effects. Expansion by about 5 per cent (sufficient to crack the crucible) occurs in gold with 27 atomic per cent germanium. It is not enough to postulate that the expansion of germanium outweighs the shrinkage of gold. Interpolated densities at the melting point predict a zero change in volume on solidification at 40 atomic per cent germanium. Thus the alloys richer in gold should shrink on solidification whereas at 27 atomic per cent germanium they expand. Therefore the liquid structure has an influence on the solidified product as it gives rise to an increase in volume of the casting.

From the industrial point of view expansion on solidification in gold alloys is of potential practical importance in that it may lend itself to accurate casting and the elimination of flash/wastage. Further, as shown by preliminary experiments at Fulmer, the eutectic temperature may be raised to as high as $700^{\circ} \mathrm{C}$ by ternary alloying (15). Manipulation of compositions in the ternary alloys is expected to modify volume changes in the direction of expansion on solidification.

\section{Rapid Quenching from Liquid}

Practical casting rates have an upper limit of $10^{2} \mathrm{deg} \mathrm{s}^{-1}$. Of the many factors controlling solidification one which will have a strong influence on the structure of the resulting solid is the cooling rate. Clearly the more rapid the cooling the less opportunity the atoms have to diffuse to the growing solid interface, and thus the greater the influence of the liquid structure on that of the resultant solid. Hence increases in rates of cooling should modify conventional equilibrium products. This has been abundantly confirmed by the use of higher rates, up to $10^{10} \mathrm{deg} \mathrm{s}^{-1}$, where the atomic packing of the solid product can be more closely allied to that of the liquid phase than that of the normal crystalline solid. This is a relatively new branch of metallurgy which followed from the development of rapid cooling techniques.

Techniques of rapid cooling were pioneered fifteen years ago by Professor Pol Duwez and his colleagues at Caltech. One of the first products prepared was an alloy of gold with 25 atomic per cent silicon quenched from $1300^{\circ} \mathrm{C}(16)$. The X-ray pattern gave no evidence of the equilibrium crystalline structures. Instead the spectrum resembles that for liquid 
alloys and the product was identified as a "glass", the first metallic glass to be made. Evidently very high rates of cooling will suppress normal crystallisation.

This result, only one of many which showed unusual crystalline phases as well as "glasses", established liquid quenching as a route to novel alloys. The essential feature of liquid quenching, known popularly as "splat-cooling", is rapid heat extraction so that products can have dimensions of no greater than $100 \mu \mathrm{m}$ in one direction at least. Originally made by rapid ejection of liquid droplets against highly conducting surfaces chilled by liquid nitrogen, splat-cooled samples were thin, irregular foils. More advanced methods enable the semi-continuous production of commercial grade wire or ribbon by cooling at rates of $10^{5} \mathrm{deg} \mathrm{s}^{-1}$ and over to room temperature, and at speeds of $30 \mathrm{~m} \mathrm{~s}^{-1}$ (17). In many cases the metastable products (glassy or crystalline) have a prolonged life, even at room temperature.

\section{Metastable Products of Rapid Quenching}

Splat-cooled products now constitute a multifarious array of materials, some crystalline, some "glassy". Limited solid solutions can sometimes be extended on splat-cooling. Solid gold dissolves 23.5 atomic per cent cobalt but splat-cooled goldcobalt alloys can contain up to 42 atomic per cent of cobalt in solution (18). The structures of some of the gold "splats" are already well-known in classical metallurgy although they do not occur as stable gold compounds in the equilibrium diagrams. For instance the $\gamma$-brass structure, a Hume-Rothery electron compound and a common structure in solid noble metal alloys, is not found in the equilibrium diagram of the gold-tin system. When gold alloys with 20 to 29 atomic per cent tin are splat-cooled the product may be identified as the missing $\gamma$-phase (19). The gold-silicon system has no stable inter-metallic phases. Yet gold alloys with 16 or 25 atomic per cent silicon have recently been splat-cooled to give a metastable phase identical in symmetry with that of the well-known $\beta$-manganese electron compound also known as the $\mu$ phase (20). The analogous gold-germanium simple eutectic system will give hexagonal $(\zeta)$ or body-centred tetragonal intermetallic phases, depending on the quench temperature and on composition $(21,22)$. Figure 1 shows the distribution of these phases in the gold-germanium system.

More unusual phases, never seen before in the equilibrium diagrams of gold, have been made by splat-cooling simple eutectic systems of gold with antimony, tellurium, etc. Thus gold-antimony gives both the familiar close-packed hexagonal crystal symmetry ( $\zeta$-phase) at 15 atomic per cent antimony and a simple cubic structure ( $\pi$-phase) at 76.6 atomic per cent (23). The appearance of the latter structure in gold splats is particularly intriguing as it was formerly known only in the rare and very unstable metal polonium. The metastable $\pi$-phase has novel electronic properties absent from equilibrium alloys. Superconductivity at temperatures up to $7 \mathrm{~K}$ is observed (24).

For a review of splat-cooling methods and products the reader is referred to Jones (25). A comprehensive classified bibliography has been issued by Jones and Suryanarayana (26).

With reference to atomic packing in the liquid the following postulates are proposed.

(1) The metastable crystalline gold phases are, as a rule, more close-packed than the corresponding equilibrium alloys of the same composition, provided the alloy system is simple eutectic.

(2) There is a parallelism between the packing in the metastable phases, and the packing in the equilibrium liquid phase.

To illustrate these points we can make use of the volumes per atom in the metastable crystalline solids, calculated from the measured lattice parameters and plotted as a function of composition in Figure 2. It can be seen that these metastable phases are more close-packed than the corresponding equilibrium

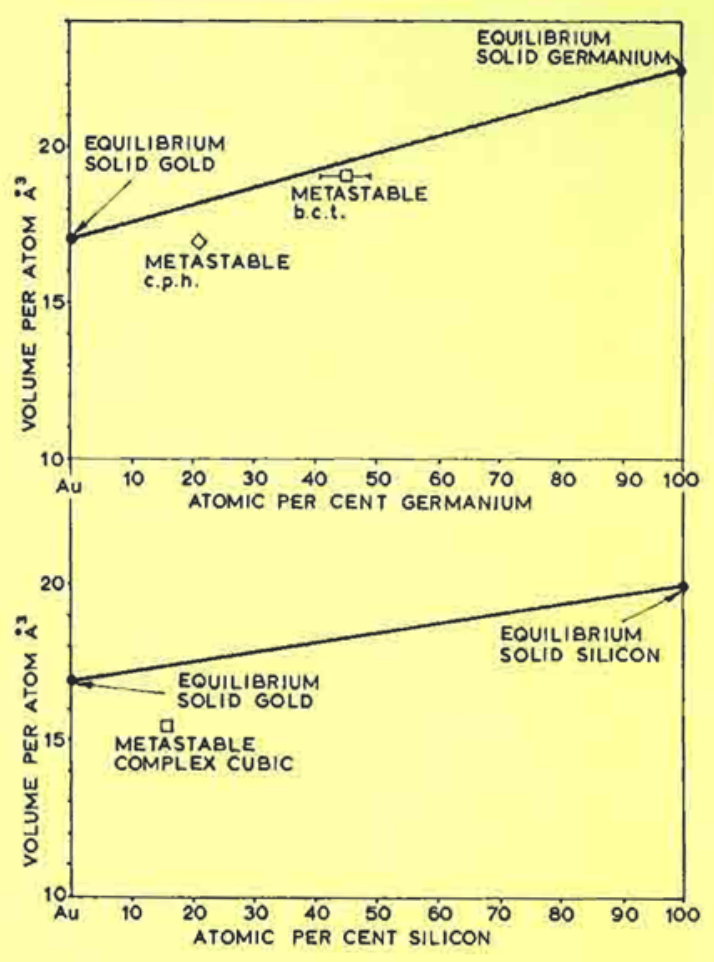

Fig. 2 The experimental volumes per atom at room temperature of metastable crystalline phases in the gold-silieon and gold-germanium systems shown as a function of composition 
alloy structures, as represented by the straight line interpolation between the values for the component elements at room temperature. This result follows from our thesis that the liquids are more close-packed than interpolation would predict.

\section{Applications}

A considerable body of work is now available on the properties of the metastable phases. The expense of gold accounts for the fact that experiments with gold alloys have not proceeded beyond the laboratory stage. However, the glassy state in metals has attractions for materials technology. The absence of long-range crystal structure implies an absence of grain boundaries and lattice defects which means fewer weak points for corrosive attack. Likewise, the absence of slip mechanisms in metallic glasses would lead one to expect enhanced strength parameters and several papers have appeared on this topic (27). Glassy metals are harder with better wear resistance. Commercial exploitation of the materials is still some way off but continuous production in ribbon and fibre form of base-metal glasses (chiefly iron alloys) has already commenced.

The potential of gold in this field has not been explored in depth, which underlines the fact that gold is underrated as an industrial material in spite of its being indispensable in so many applications. It is hoped that as more is discovered about the metallic glasses, the wealth of theoretical and fundamental data on liquid gold and its alloys will be put to good use in practical applications.

\section{References}

1 N. W. Ashcroft and J. Lekner, Phys. Rev., 1966, 145, (1), 83

2 N. C. Halder and P. Jena, f. Chem. Phys., 1972, 57, (5), 1830

3 S. P. Isherwood and B. R. Orton, Ұ. Phys, C., 1972, 5, (21), 2977

4 R. M. Waghorne, V. G. Rivlin and G. I. Williams, $A d v$. Phys., 1967, 16, (62), 215

5 R. M. Waghorne, V. G. Rivlin and G. I. Williams, f. Phys. F: Metal Phys., 1976, 6, (2), 147

6 J. R. Wilson, Metall. Rev., 1965, 10, (40), 381

7 A. R. Ubbelohde, "Melting and Crystal Structure", Clarendon Press, Oxford, 1965, p. 170 et seq.

8 V. M. Glazov, S. N. Chizhevskaya and N. N. Glagoleva, "Liquid Semiconductors", Plenum Press, New York, 1969 , p. 323

9 S. P. Isherwood, B. R. Orton and A. Mănăilă, $尹$. NonCryst. Solids, 1972, 8, 691

10 Y. Waseda and K. Suzuki, Z. Physik, 1975, B20, (4), 339

11 W. Hume-Rothery and E. Anderson, Phil. Mag., 1960, $5,(52), 383$

12 H. S. Chen and D. Turnbull, f. Appl. Phys., 1967, 38, (9), 3646

13 D. Turnbull, f. Phys. (Paris), Colloq., 1974, 35, Pt. 4, 1

14 R. P. Anantatmula, A. A. Johnson, S. P. Gupta and R. J. Horylev, $\mathcal{F}$. Electron. Mater, 1975, 4, (3), 445

15 V. G. Rivlin, Fulmer Research Institute, Progress Report, R513/2/January 1975

16 W. Klement, R. H. Willens and P. Duwez, Nature, $1960,187,(4740), 869$

17 H. S. Chen and C. E. Miller, Rev. Sci. Instr., 1970, 41, (8), 1237

18 W. Klement, Trans. AIME, 1963, 227, 965

19 B. C. Giessen, Z. Metallkunde, 1968, 59, (10), 805

20 C. Suryanarayana and T. R. Anantharaman, Mater Sci. Engng., 1974, 13, (2), 73

21 T. R. Anantharaman, H,-L. Luo and W. Klement, Nature, 1966, 210, (5040), 1040

22 M. G. Scott, Mater. Sci. Engng., 1975, 18, (2), 279

23 A. K. Jena, B. C. Giessen, M. B. Bever and N. J. Grant, Acta Metall., 1968, 16, (8), 1047

24 C. C. Tsuei, H.-C. Yen and P. Duwez, Phys. Lett., 1971, $34 \mathrm{~A},(2), 80$

25 H. Jones, Rep. Prog. Phys., 1973, 36, (11), 1425

$26 \mathrm{H}$. Jones and C. Suryanarayana, $\mathcal{F}$. Mater. Sci., 1973, 8, (5), 705

27 C. A. Pampillo, f. Mater. Sci., 1975, 10, (7), 1194

\section{Characteristics of Gold-Copper-Cadmium Electrodeposits}

Ternary gold-copper-cadmium electrodeposits from an alkaline cyanide solution have been established for some years and have found applications mainly in the decorative field. A typical composition is 75 per cent gold with 15 per cent copper and 10 per cent cadmium, but minor changes in composition can affect the characteristics of the deposits and considerable care is required in controlling the electrolyte.

One of the advantages of this alloy deposit is of course the economy in gold, but for industrial or electronic applications this is outweighed by the high contact resistances developed in use. None the less, an investigation of its characteristics by comparison with those of a high purity gold and a 99.8 per cent gold 0.2 per cent cobalt deposit, reported by J.-J. Robert of Lea-Ronal France (Galvano-Organo, 1976, (461), 33-36 and (462), 114-117) adds to our knowledge.

Naturally the Vickers hardness of the ternary deposit is significantly greater than either of the straight golds tested, while its resistances to wear was also found to be superior. Ductility tests, carried out by two methods-one on plated copper wires bent over small mandrels and the other by spiralling plated strips-showed distinct improvements with the ternary alloy deposit.

But in the vital matter of contact resistance the results obtained by Robert-and supplemented by those of others who have studied this electrolyteconfirm the unsuitability of this type of deposit for applications in which minimal values are essential. Measurements with a milliohmeter at room temperature and with increasing contact pressures showed substantially higher readings with the ternary deposit. Specimens subjected to a temperature of $100^{\circ} \mathrm{C}$ in air for increasing lengths of time also showed an appreciable rise in contact resistances after 200 hours, while the pure gold and the cobalt-gold gave much smaller increases in contact resistance.
L. B. $\mathrm{H}$. 